This item was submitted to Loughborough's Research Repository by the author.

Items in Figshare are protected by copyright, with all rights reserved, unless otherwise indicated.

\title{
The relationship between productive and counterproductive work behaviour across four European countries
}

PLEASE CITE THE PUBLISHED VERSION

http://dx.doi.org/10.1080/1359432X.2012.673280

\section{PUBLISHER}

(C) Taylor \& Francis

\section{VERSION}

AM (Accepted Manuscript)

\section{PUBLISHER STATEMENT}

This work is made available according to the conditions of the Creative Commons Attribution-NonCommercialNoDerivatives 4.0 International (CC BY-NC-ND 4.0) licence. Full details of this licence are available at: https://creativecommons.org/licenses/by-nc-nd/4.0/

\section{LICENCE}

CC BY-NC-ND 4.0

\section{REPOSITORY RECORD}

Coyne, lain J., Domenica Gentile, Marise P. Born, Nevra C. Ersoy, and Maria Vakola. 2019. "The Relationship Between Productive and Counterproductive Work Behaviour Across Four European Countries". figshare. https://hdl.handle.net/2134/22454. 
Running head: RELATIONSHIP BETWEEN OCB AND CWB

The Relationship Between Productive and Counterproductive Work Behaviour Across

Four European Countries 


\begin{abstract}
Research suggesting a similar but different relationship between Organisational Citizenship Behaviour (OCB) and Counterproductive Work Behaviour (CWB) is dominated by North American samples. Little evidence exists on whether these findings are replicated in other countries. To assess if a similar pattern emerged, we used the Social Axioms model (Bond et al, 2004) as a cultural framework and surveyed employees in the UK (105), The Netherlands (203), Turkey (185) and Greece (70) on the relationship between OCB and CWB, and the relationship between these behaviours and personality, justice and commitment. Analysis supported a multidimensional structure to OCB and CWB and indicated a non-bipolar relationship between these behaviours. Culturally, somewhat different to OCB research in general, we find support for a convergence perspective across countries. Conceptually, linguistically and structurally the scale assessing $\mathrm{OCB} / \mathrm{CWB}$ was shown to be equivalent across countries and a non bi-polar pattern of relationships was consistent across countries. Overall, findings imply a universal nature to the relationship between OCB and CWB across societal cultural groups.
\end{abstract}

Keywords: OCB, CWB, Culture, Invariance 
The Relationship Between Productive and Counterproductive Work Behaviour Across Four

\section{European Countries}

Organizational Citizenship Behaviour (OCB) and Counterproductive Work Behaviour (CWB) are typically seen as discretionary, non-task in nature and, coupled with task performance, represent three broad domains of job performance (Rotundo \& Sackett, 2002). Although initially examined from separate perspectives, researchers are becoming more interested in the commonality between the two constructs (Dalal, 2005; Hunt, 1996; Spector, Bauer, \& Fox, 2010). However, even though empirical evidence is more supportive of a multidimensional, distinctive nature to $\mathrm{OCB}$ and $\mathrm{CWB}$; the majority of this research has focused on North American samples and we have little systematic evidence on whether similar relationships between these behaviours emerge across different cultures.

Experiences of both productive and counterproductive behaviours may differ across countries as a result of different norms, beliefs and values within the countries. Researchers need to ensure that cultural considerations become inherent within the development of OCB and CWB research and to clarify if meaningful differences emerge across cultures. Therefore, given the scarcity of intercultural research on both OCB and CWB, the current study adopts a cross-cultural approach to examine the relationship between OCB and CWB across four European countries.

\section{The Merging of OCB and CWB Research}

Although the research on OCB and CWB has increased dramatically in the past 20 years, it is has tended to follow distinct paths, with researchers proposing different definitions and concepts to capture behaviours that are positive or negative to the organization. This is evidenced by the plethora of concepts and conceptual models proposed to capture OCB (e.g. Coleman \& 
Borman, 2000; Organ, 1988; Smith, Organ, \& Near, 1983; Van Scotter, 2000) and CWB (e.g. Bennett \& Robinson, 2000; Gruys \& Sackett, 2003; Marcus, Schuler, Quell, \& Humpfner, 2002). Models within each domain have tended to be viewed in isolation, yet there is recognition that facets can be combined into conceptually distinct subgroups of those directed towards the organization and those directed towards individuals (Bennett \& Robinson, 2000; Coleman \& Borman, 2000; Gruys \& Sackett, 2003). This similarity in model structure has led to an increasing interest in examining if $\mathrm{OCB}$ and CWB are related.

Early on a 'unidimensional-opposite' stance promoted the notion of a unidimensional concept of voluntary work behaviour with a bi-polar relationship between OCB and CWB. This was based on conceptual notions of OCBs being positive for an organization and CWBs as negative; theoretical arguments based on norms of reciprocity, social exchange and the psychological contract (Bennett \& Stamper, 2001); and empirical studies showing strong negative relationships between OCB and CWB (Sackett, 2002) and analogous relationships with antecedents such as organizational commitment (Lepine, Erez, \& Johnson, 2002) and justice (Bechtoldt, Welk, Hartig, \& Zapf, 2007).

However, evidence of moderate negative relationships (O’Brien \& Allen, 2008) or even positive relationships (Dalal et al. 2009) between OCB and CWB and limited support for analogous relationships with personality, attitudes and emotions (Dalal, 2005; Sackett, Berry, Wiemann, \& Laczo, 2006) started to cast doubt on this unidimensional hypothesis. In addition, theoretical arguments based on emotions (Spector \& Fox, 2010a) and attributions (Spector \& Fox, 2010b) have recently been offered as explaining possible positive relationships between OCB and CWB. 
Further, our conceptions that OCBs are always positive and CWBs always negative are also being challenged. Although evidence for the positive organizational and individual outcomes of OCB (Podsakoff, Whiting, Podsakoff, \& Blume, 2009) and the negative outcomes of CWB (Rogers \& Kelloway, 1997) exists; other research has suggested that OCB emerges from non-positive motives (Bolino, Turnley, \& Niehoff, 2004), has negative consequences for individuals (Bolino, Turnley, Gilstrap, \& Suazo, 2010), and that CWB may sometimes be constructive (Galperin \& Burke, 2006).

Currently, the evidence is more supportive of a multidimensional, difference nature to OCB and CWB. However, we are still at an early stage in explaining why such a relationship exists and why different empirical findings emerge. In particular, one major issue with the current research is the domination of US studies and limited consideration of whether the research extends to other national cultures. Those studies directly testing the relationship between OCB and CWB have been based on US (Dalal et al., 2009; O’Brien \& Allen, 2008; Sackett, Berry, Wiemann, \& Laczo, 2006; Spector, Bauer, \& Fox, 2010) or Canadian samples (Kelloway et al. 2002). In fact, of the non-US samples included in the often cited meta-analysis by Dalal (2005), $4.1 \%$ were reported to be from Canada and South Africa, with $2 \%$ from other countries. Critically, not all were nationals of the country the data was collected in (e.g. some data were from Americans living in these other countries).

\section{Culture and $\mathrm{OCB} / \mathrm{CWB}$}

To date, we could not find any research assessing if the 'multidimensional difference nature' approach to OCB and CWB, supported in US research, also emerges in other cultural contexts. This is not surprising because, in comparison to research more generally on $\mathrm{OCB} / \mathrm{CWB}$, the impact of the cultural context on these behaviours has not been as extensively 
studied. Even when considered, the focus has tended to be on OCB and not CWB. Initially, Farh, Earley, \& Lin (1997, p.421) argued that "we know little about citizenship behaviour in a global context." Three years later in their comprehensive review paper on OCB, Podsakoff, Mackenzie, Paine, \& Bachrach (2000) further highlighted the need to consider the cultural context in OCB research. Even as recent as 2008, Kwantes, Karam, Kuo and Towson, continued to bemoan the paucity of research on culture and OCB.

Culture has been mooted to potentially play a key role in OCB as a result of its impact on: the forms of OCB seen across cultures; the level of engagement in OCB across cultures; the relationship between OCB and antecedents and outcomes; and our understanding of how OCBs are enacted across cultures (Podsakoff et al., 2000). To some extent empirical evidence in relation to societal and/or individual cultural values has supported these propositions, with differences seen in the dimensionality of OCB (Farh et al, 1997; Farh, Zhong, \& Organ, 2004); relationships with various antecedents (Cem Ersoy, Born, Derous, \& van der Molen, 2011; Coyne \& Ong, 2007); the level of engagement of OCB (Moorman \& Blakely, 1995); and in perceptions of the in-role/extra-role nature to OCB ( Kwantes, Karam, Kuo, \& Towson, 2008; Lam, Hui, \& Law, 1999).

Theoretically, Hofstede's (1980) concepts of individualism-collectivism and power-distance have been proposed as explanatory mechanisms to account for differences in OCB across cultural values. Individualism refers to weakly linked social frameworks, where members take responsibility only for themselves and their immediate family. Collectivist cultures have stronger bonds within a larger in-group, where altruistic behaviour occurs for the good of the group. Power distance "is a measure of the interpersonal power or influence between [boss] B and [subordinate] S as perceived by the least powerful of the two, S" (Hofstede, 1980 p.70-1). 
Members of high power-distance countries tend to be more accepting of unequal power distribution. As a result, Paine \& Organ (2000) hypothesized that collectivist cultures would demonstrate more OCBs than individualist cultures, because OCBs would be common, normal behaviour within such cultures. Additionally, because OCBs may go beyond what is expected by a leader and hence is perceived as a challenge to the leader; they also argued that high power distance cultures are less likely to engage in OCB behaviours. Empirically, Moorman and Blakely (1995) and Van Dyne et al. (2000) have supported the notion of higher levels of OCB within collectivist cultures. However, contrary to Paine and Organ, evidence has indicated that high power distance cultures see OCBs as part of their job and hence likely to show higher levels of engagement than lower power distance cultures (Lam, Hui, \& Law, 1999).

In considering cultural influences on $\mathrm{CWB}$, there is reason to hypothesise that the influences of culture on OCB theorised by Podsakoff et al., 2000 should apply to CWB. Yet, these influences have not been widely examined. Further, notions of collectivism and power distance have not been as readily adopted as explanatory mechanisms in the CWB research area. One could propose an opposite relationship between these cultural values and CWB as compared to OCB; however, this would assume OCB and CWB are bi-polar opposite constructs - which, as already shown is not supported in the US literature. Overall, while CWB studies have been conducted in different countries (e.g. Lee, Ashton, \& Shin, 2005; Marcus, Schuler, Quell \& Humpfner, 2002), national culture has received little attention in relation to CWB (Spector \& Fox, 2005).

Johns and Xie (1998) considered cross-cultural differences in absenteeism (a form of CWB) between Canadian and Chinese employees. Similarities between the samples emerged in perceptions of absence levels and ratings of reasons why absence occurred. More recently, 
Rotundo \& Xie (2008) researched conceptualizations of CWB and importance of the behaviour in job performance ratings also across Canadian and Chinese samples. Again, similarities across cultures emerged, although the Chinese sample did weight CWB lower than the Canadian sample in terms of assessing overall job performance. Both these studies support what Rotundo \& Xie refer to as a convergence perspective in that: “...industrialization necessitates certain managerial practices regardless of the culture in which it occurs" (p.857). By contrast, cultural influence research on OCB seems to adopt more a divergence perspective: "that work and personal values are primarily the product of societal-cultural influences... [and]...despite globalization and any economic similarities between nations, individuals hold onto the nation's cultural values..." (p.857)

This leaves us with somewhat a dilemma. There is a need to research more cultural influences on OCB and CWB, especially in terms of the relationship between them. However, it is difficult to create specific hypotheses about the impact culture will have on this relationship because: a. comparatively there is a lack of an evidence-base in CWB research to suggest what impact culture may have on this behaviour; b. OCB research suggests cultural values influence this behaviour (divergence perspective) and CWB research suggests it does not (convergence perspective). Therefore, similar to Rotundo and Xie (2008) we do not state specific predictions but rather suggest a more general research question of:

To what extent is the multidimensional/difference relationship between $O C B$ and $C W B$ seen in other societal cultures?

\section{Cultural Framework}

As discussed, most OCB research adopts Hofstede's collectivism and power distance concepts as their cultural framework. In the current study, we have chosen to use the cultural 
level Social Axioms model (Bond et al, 2004) to select countries which differ in these beliefs. In this model, cultural level social axioms are distinguished on the basis of two dimensions: Societal Cynicism (SC), characterized by a negative view of human behaviour, high equity perceptions, low conscientiousness and more disagreement; and Dynamic Externality (DE), related to positive affect, a tendency to get along with others, and status seeking.

We chose this model for a number of reasons. Firstly, as theoretical development is not strong enough to suggest notions of collectivism and power distance influence CWB, there is no reason to expect that such ideas will translate from OCB to CWB research - especially as CWB is not necessarily opposite to OCB. Secondly, Kwantes et al. (2008) argue that social axioms are based on individual beliefs which are more accessible, concrete and comprehensive than cultural values. As a result, they posit that axioms would be a better predictor of attitudes and behaviour than cultural values (e.g. collectivism). Thirdly, we would expect a relationship between SC and CWB (because of its facets of low conscientiousness, high disagreement and low job satisfaction which have been shown to relate to CWB); and between DE and OCB (as it relates to variables of agreeableness, positive emotion and cooperation which characterize OCB).

To reiterate, to date there is a comparative lack of research considering the influence of cultural norms and beliefs on OCB and CWB and none which focuses on the relationship between these two behaviours. The current study aims to fill this gap using the social axioms model as a framework to assess the relationship between OCB and CWB across cultures.

\section{Method}

Countries were chosen using the Social Axioms model (Bond et al, 2004) based on cultural level social axioms of Societal Cynicism (SC) and Dynamic Externality (DE). The researchers in the UK initially used the scatter plot of nations based on SC and DE provided by Bond et al., to 
identify countries within which to survey. Countries were chosen and researchers contacted in each. From this we identified three countries: the UK within the lower SC and DE quadrant; Turkey the lower SC/higher DE quadrant; and Greece the higher SC/lower DE quadrant. We were unable to obtain a sample from the higher SC/DE quadrant.

Initially, we sought one multi-national organization which operated in all these countries, but were unsuccessful. To control organizational sector, we aimed to survey organizations across the same broad sector. This was achieved for the Turkish and Greek samples, who were both from the manufacturing sector. However, the UK sample emerged from a different sector so we also included a sample from the Dutch subsidiary of the UK organization for comparison. Although culturally, both the UK and the Netherlands are clustered in the same social axioms quadrant, the inclusion of a Dutch sample allowed us to consider the impact of organizational sector on the results.

\section{Participants.}

In the UK and Netherlands samples, an email with a web link to an online survey was sent by HR representatives to full time staff and casual workers within a leisure and entertainment sector organization involved in planning and managing events worldwide. After screening for incomplete responses, 105 UK employees completed the online survey (44\% female and 53\% male) with a mean age of 31.9 years $(\mathrm{SD}=11.9)$ and mean tenure within the organization of 3.3 years $(\mathrm{SD}=4.1)$. The majority of respondents $(76 \%)$ were casual employees involved in events support duties and other job roles included casual supervisors (7.6\%), permanent, mostly administrative, staff (6.7\%) and management (6.7\%). The final Dutch sample comprised 203 employees $(28 \%$ female $)$, with a mean age of 33.9 years $(\mathrm{SD}=12.0)$ and mean tenure within the organization was 4.5 years $(\mathrm{SD}=4.4)$. Most $(67.2 \%)$ were security personnel (both permanent 
and casual staff), $10.2 \%$ were service personnel (permanent and casual staff), and only $1.2 \%$ were management and office workers.

The Turkish organization was involved with the production of poultry and soy products. A paper and pencil questionnaire was administered to a volunteer sample of 200 and after screening, a final sample of 185 employees was used. A third of the sample were female, with an average age of 29.0 years $(\mathrm{SD}=5.9)$ and tenure within the organization of 2.8 years $(\mathrm{SD}=2.6)$. The sample consisted of blue collar employees (56.2\%), office employees (15.1\%), professionals $(10.3 \%)$, middle managers $(7.6 \%)$, senior managers $(5.9 \%)$, and technicians $(3.8 \%)$.

Data were collected in two Greek pharmaceutical organizations and subsequently combined together. In the first organization, a HR representative distributed paper questionnaires to employees, but only 19 questionnaires were collected, of which 17 were used for the final analysis. In the second organization, 98 invitations to complete the online survey were sent by a Greek researcher, and of these 53 responded and completed the whole survey. The final sample of 70 employees, comprised $54 \%$ female, with an average age of 35.6 years $(\mathrm{SD}=8.6$ years) and average tenure within the organization of 6.3 years $(\mathrm{SD}=5.5$ years $)$. In terms of job levels, $41.4 \%$ of respondents were middle managers, $40 \%$ employees, $11.4 \%$ senior managers, and $7.1 \%$ supervisors.

Significant differences between samples emerged in age $F(3,540)=11.42, \mathrm{p}<.001$, tenure $\mathrm{F}(3,545)=15.03, \mathrm{p}<.001)$ and gender $\left(\chi^{2}(3)=20.02, \mathrm{p}<.001\right)$. Post-hoc Tukey HSD analyses indicated that the Turkish sample were significantly younger than the Dutch and Greek samples and that the Turkish and Greek samples were significantly different from the UK and Dutch samples in terms of tenure. The UK and Dutch samples were not different on demographic variables. 


\section{Materials and Procedure}

The Voluntary Workplace Behaviour Scale (VWB) (Coyne \& Gentile, 2006) was used to measure OCB and CWB. This scale comprises 50 items and measures the extent to which employees have engaged in certain behaviours in the previous 12 months, using a 6-point response scale (from 'Never' to 'Very often'). Unlike previous research which has used scales specifically developed within the OCB and CWB domains, the VWB scale was developed to assess a five-factor model of voluntary workplace behaviours based on a individualorganizational/productive-counterproductive structure. Facets include, organizational (CWBO) and interpersonal (CWBI) counterproductive behaviour; organizational productive behaviour (OCBO); and two facets of interpersonal productive behaviour (interpersonal courtesy and interpersonal helping). The advantage of this scale is that it considers both OCB and CWB together within a dimensional structure considered to represent both behaviours (e.g. the notion of organizational and interpersonal dimensions) rather than adopting existing separate scales of measurement based within each domain. The other advantage is that the VWB scale purposely omitted overlapping items in its construction.

A self and other reported version was created, but due to the lack of responses for the other reported version, data on self-reports is presented here. This is less problematic as supervisor ratings inflate the negative relationships between $\mathrm{OCB}$ and $\mathrm{CWB}$ more than do self ratings (Dalal, 2005; Spector, Bauer, \& Fox, 2010).

Given that the VWB scale is new scale previously developed in the UK and given that the main focus of the research to assess the cultural aspect of OCB and CWB, it was important to assess the equivalence of the scale across cultures. To do this, we adopted the ITC Guidelines on Adapting Tests (2000) (http://www.intestcom.org/Guidelines/Adapting+Tests.php) as the 
guiding framework to translate and adapt the VWB scale from English into Greek, Turkish and Dutch target languages. We followed a step-by step procedure similar to that outlined by Hambleton \& Patsula (1999) to create three new language versions of the VWB scale based on an assessment of conceptual equivalence, linguistic equivalence and structural equivalence.

Conceptual equivalence. As the VWB scales was developed in the UK, conceptual equivalence was assessed across the other countries using a number of methods. Firstly, published research literature and conference papers were briefly reviewed to examine the extent these concepts had been empirically studied in the three target cultures. This provided some initial evidence as to the amount of overlap between the different countries in the constructs being assessed and whether cross-cultural comparisons would be appropriate. Following this, lead researchers in each country who helped with translation and data collection were asked to provide their thoughts on the concepts of OCB and CWB behaviour generally, as well as on the VWB scale specifically. Researchers were asked to consider: 'To what extent does the construct of voluntary workplace behaviour exist in your country and especially the notion of OCB and CWB behaviour? In particular: Are there any specific cultural factors to consider? Are OCB and CWB reflected similarly in your country? Are the 5-factors in the VWB scale reflected in your country? Is an adaptation of the VWB scale appropriate for your country?'

Using PsychInfo and Web of Science databases, examples of OCB and CWB research was investigated in three target countries. Search terms included 'counterproductive behaviour', 'work deviance', 'organizational citizenship behaviour' and 'contextual performance' with country (e.g. Netherlands, Dutch, Greece, Greek, Turkey, Turkish) and 'culture' as added search terms (we included articles up to and including 2009). Additionally, we included some conference papers with data on the concepts. This search was neither a systematic nor a 
comprehensive literature review; rather the aim was to obtain some evidence for the concepts in Greek, Turkish and Dutch samples.

This analysis yielded 20 published papers or conference papers. Evidently, OCB appears to have been researched more frequently in the three countries than CWB. In fact, for Greece only one qualitative conference paper was found that referred to CWB within a Greek sample. From the 17 studies adopting a quantitative method, 14 (82\%) used well-established (mostly USdeveloped) scales to assess either OCB or CWB related constructs. Some provided factor analytic evidence for the use of the scale in the specific sample and all provided reliability data to support the use of the scale in the sample.

Analysis of responses from researchers in the three countries also supported the conceptual equivalence of the VWB scale. They felt that the concepts of OCB and CWB and the five factors of the VWB scale were reflected in their countries. There was also agreement that an adaptation of the VWB scale would be relevant for their countries. In relation to the question of the impact of cultural values on voluntary work behaviour, both the Greek and Turkish researchers suggested that the hierarchical nature of both cultures may impact on the extent to which people engage in different behaviours or the extent to which they are viewed as in-role or extra-role.

Overall, given the fact that published research reviewed has studied the concepts of OCB and CWB in the three target countries and given that researchers in each country appear to indicate a scale based on these concepts would be appropriate in each culture; evidence of conceptual equivalence of the VWB has been established. On the basis of this evidence, it seems reasonable to conclude that VWB, as a concept, can be explored in the Netherlands, Turkey and Greece as well as the UK. 
Linguistic equivalence. To develop a linguistically-equivalent scale, a panel-based forward translation approach was used to translate and adapt the VWB scale from English into the three target languages. Within each country three people were chosen who were well versed in both the source and target language; and had an understanding of the culture of the target language. In the majority of cases, individuals also had a background in occupational psychology and some understanding of testing and/or scale translation. The three individuals in each country initially worked independently translating and adapting the English version of the VWB scale into their target language, resulting in three separate translations for each country. Translators were informed that they needed to ensure that the translation of each item fitted the linguistic features of the target language, whilst maintaining the conceptual equivalence of the item. Panel members then discussed their translations and agreed on a final version.

Once a final agreed version was produced this was then back-translated into the source language by one of the researchers and sent to the lead researcher for notification and verification. Main researchers in each country were then asked to comment on the content of items, wording of questions, response format and clarity of instructions for the VWB scale as it related to their country. They were also asked to note where (if applicable) they felt that participants may have difficulty in understanding items in the scale. Finally, similar to Van de Vijver and Jeanrie (2004), researchers were then asked: 'Compared to the meaning of the original item, the meaning of the translated item is: $1=$ identical, $2=$ rather similar, $3=$ rather different or 4=different'.

In all cases, researchers judged the item content, wording, response format and clarity of instructions of the translated VWB scales to be appropriate and no problems were identified. In terms of comparing the meaning of the translated item to the original item, in the majority of 
cases across all countries the translated items were rated as 'identical' or 'rather similar' to the original items. Only three incidences of items not rated as 'identical' or 'rather similar' emerged across the three countries. Two of the cases were the use of plural rather than singular phrases in the Greek version and this did not substantially change the meaning of the item. The other case was within the Turkish version of the scale. The item 'Helped to keep the peace with other employees' was translated into 'Put effort to keep peace with others' and was rated as 'rather different'. However, there is little change in meaning here and the item was retained. Structural equivalence. Structural equivalence was assessed using SEM multigroup equivalence analysis via EQS 6.1 (Bentler, 2006). Equivalence testing comprises a series of steps whereby one tests for the equivalence of factor loadings, factor covariances, item intercepts (observed means) and latent factor means. Whereas the two former steps are based on analysis of covariance structures (COVS), the latter two are based on the analysis of means and covariance structures (MACS). A hierarchy of steps was adopted where equality constraints imposed on select parameters became increasingly more stringent. Presented with findings of nonequivalence, related equality constraints were deleted and these parameters freely estimated in accordance with recommendations for partial measurement invariance (see Byrne, Shavelson, \& Muthen, 1989). Findings from this are presented in the results section.

Antecedent variables. We also included antecedent variables similar to that seen in previous research (e.g. Dalal, 2005; Sackett et al., 2006) in order to be able to make a more direct assessment of the influence of cultural values. Where language versions of the following scales were not available, we used a back translation approach to create target language versions with the same researchers as described previously. 
The Big Five personality dimensions of Consciousness, Extraversion, Emotional Stability, Agreeableness and Open to Experience were each measured by 10 -item versions of each scale of Goldberg et al. (2006) Big Five factor markers in the International Item Pool. Participants were asked to indicate how accurate or inaccurate each statement was in describing them, using a 5point response scale (from 'Very inaccurate' to 'Very accurate'). In the Dutch version a different response scale that better reflected the meaning in the Dutch language was used and participants were asked to indicate their level of agreement or disagreement with each statement (from 'Strongly disagree' - 'Volledig oneens' - to 'Strongly agree' - 'Volledig eens'). Alpha levels across scales and countries ranged from .65 to .87 with a median of .75 .

Similar to Sackett, Berry, Wiemann and Lazco (2006) we chose the Big 5 framework to allow us to better determine if the pattern of relationships seen in one domain (e.g. CWB) is replicated or not in the other domain (OCB). As these authors posit, researchers can use the supportive evidence showing relationships between CWB and Conscientiousness, Agreeableness, and Emotional Stability and the lack of support for Extraversion and Openness to Experience as a comparator for assessing relationships with OCB. A similar, but opposite relationships with these five factors should emerge for OCB as compared to CWB under a non-bipolar hypothesis.

Job attitudes were assessed in terms of justice and commitment. Procedural and distributive justice were measured respectively by the Formal Procedures Scale (Moorman, 1991) and the Distributive Justice Scale (Price \& Mueller, 1986). The former consists of seven items rating the extent to which an organisation uses fair procedures; the latter, comprises five items and measures the extent to which employees believe that rewards are related to performance inputs. For both scales a 7-point Likert scale was used, from 'Strongly disagree' to 'Strongly agree'. 
Alpha reliability estimates for procedural justice ranged from .87-.91 (median $=.91)$ and for distributive justice the range was .93-.95 (median $=.94)$.

Ellemers, De Gilder, and Van den Heuvel (1998) argue that focused commitment measures might be better suited to predict behaviour than broad measures. They distinguish between career goals and team goals and developed a scale based on three different forms of commitment: career-oriented commitment, team-oriented commitment, and organisational commitment. The authors argued that the career/team goal categorization differentiates individualistic and prosocial work goals, which may have a different impact on contextual work performance. Indeed, in their study they indentified a different pattern of relationships between the three commitment factors and measures of productive and counterproductive work behaviour. Given this, and given we were able to access a Dutch version of the scale, we used the 14 item scale by Ellemers et al. and translated it into Greek and Turkish. Participants indicated their agreement or disagreement with each statement using a 7-point Likert scale (from 'Strongly disagree' to 'Strongly agree'). Median alpha level across factors and countries was .84 (range = .61-.88).

Individual social beliefs. Although we chose countries on the basis of societal level social axioms, as a check we also assessed individual differences in social beliefs using a short 25-item version of the Social Axioms Survey (M. H. Bond, personal communication, January 8, 2008). Participants were asked to indicate the extent to which they believe in each statement using a 5point scale (from 'Strongly disbelieve' to 'Strongly believe'). Individual (rather than societal) scores of social cynicism (median alpha across countries $=.73$ ) and dynamic externality (median alpha $=.68)$ were calculated.

\section{Results}

\section{Individual and societal level culture}


Before examining the main question, we first examined if societal level social axioms related to individual level social axioms. ANOVA analysis of individual differences measures identified significant differences across countries in social cynicism $(\mathrm{SC})[\mathrm{F}(3,556)=15.40, \mathrm{p}<0.001]$ and dynamic externality $(\mathrm{DE})[\mathrm{F}(3,535)=70.45, \mathrm{p}<0.001]$. Post-hoc analysis using Tukey's HSD showed the Greek sample were significantly different to all other samples in both factors; the Turkish sample were significantly different to all on DE and to the Greek and Dutch samples on SC; and the UK and Dutch samples were only significantly different in DE. Therefore, although we used nationality as a proxy for cultural beliefs, individual level measures of the same beliefs support the national cultural categorization used.

Correlations between SC and CWBO $(.16, \mathrm{p}<0.01)$ and CWBI $(.13, \mathrm{p}<0.01)$ and between DE and OCBO (.34, p<0.001), Courtesy (.20, p<0.001) and Helping (.33, p<0.001) lend support to our hypothesized relationships between these beliefs and OCB/CWB - which we used as a rationale for adopting the social axioms model.

\section{Structural equivalence of the VWB scale.}

CFA analysis and subsequent equivalence testing was undertaken in samples with at least 100 participants (therefore omitting the Greek sample). Firstly, assessment of baseline models with Maximum Likelihood estimation was conducted using EQS v6.1 (Bentler, 2006). The hypothesised five-factor model of CWBO, CWBI, OCBO, Interpersonal courtesy and Interpersonal helping was assessed first within each country. This model was then compared to: a one factor model representing a unidimensional concept of Voluntary Workplace Behaviour; a two-factor model representing global OCB and CWB behaviour factors; and a four-factor model of individual and organizationally-focused OCB and CWB. To assess model fit we used a number of statistics: standardized root mean square residual (SRMR) - small values of 0.05 or 
less reflect good fit (Byrne, 2006); root mean squared error of approximation (RMSEA) - values less than 0.05 indicate good fit and values as high as 0.08 indicate reasonable fit (Byrne, 2006) and Comparative Fit Index (CFI) - values close to 0.95 indicate good fit (Hu \& Bentler, 1999).

Initial analysis suggested kurtosis in the data and the model was re-specified using robust statistics. Further, some missing data emerged in the Turkish sample and an ML estimation method was used to account for the missing data with the Yuan-Bentler scaled statistic reported. Initial fit of the five-factor model in each country was poor (CFIs from 0.71 to 0.81 ), although fit was better than for 1, 2 and 4-factor models. Examination of the LM test indicated a large number of correlated errors, which was indicative of overlapping item content within each scale, likely as a result of each scale comprising 10 items which are not distinctively different.

To reduce item-overlap and improve fit indices, we decided to create a shorter 25 -item version of the scale. We chose this over the option of creating item parcels because simulation research has shown parcels overestimate the existence of measurement invariance (Meade \& Kroustalis, 2006). We created a development sample by including only odd numbered cases within each country $(\mathrm{N}=283)$ and a validation sample by selecting even numbered cases in each country $(\mathrm{N}=280)$. In the development sample the following criteria were used to reduce the scale to five items per factor. Within each of the five factors: items with corrected-item total correlations equal to or lower than 0.40 were omitted; items with stronger correlations with other factors than the original factor were also omitted; items with small differences between corrected-item total correlations in the original factor and other factors were omitted; if more than five items still remained, those with lowest corrected-item total correlations were omitted.

CFA analysis of the same five-factor model on the development sample showed an acceptable fit to the data $[\mathrm{Y}-\mathrm{Bx} 2=422.74(265), \mathrm{p}<0.001 ; \mathrm{CFI}=0.91 ; \mathrm{SRMR}=0.06 ; \mathrm{RMSEA}=0.05(\mathrm{CI}$ 
0.04-0.05)]. This was stronger than the other competing models (see Table 1). A similar analysis was then repeated in validation sample. Once again acceptable fit was seen to the data for a fivefactor model $[\mathrm{Y}-\mathrm{Bx} 2=389.58(265), \mathrm{p}<0.001 ; \mathrm{CFI}=0.93 ; \mathrm{SRMR}=0.06 ; \mathrm{RMSEA}=0.04(\mathrm{CI}$ $0.03-0.05)]$.

Insert Table 1 about here

CFA analysis using the revised 25-item scale was then undertaken for each country separately to assess cultural differences in model specification. The five-factor model derived from the revised 25-item scale indicated reasonable fit to the data in the UK [S-Bx2=321.16 (265), $\mathrm{p}<0.05 ; \mathrm{CFI}=0.91 \mathrm{SRMR}=0.09 ; \mathrm{RMSEA}=0.05(\mathrm{CI}$ 0.02-0.06)]; Dutch $[\mathrm{S}-\mathrm{Bx} 2=360.23$ (265), $\mathrm{p}<0.001 ; \mathrm{CFI}=0.91 ; \mathrm{SRMR}=0.07 ; \mathrm{RMSEA}=0.04(\mathrm{CI}$ 0.03-0.05)]; and Turkish samples [Y-Bx2 = 376.67 (265), $\mathrm{p}<0.001 ; \mathrm{CFI}=0.90 ; \mathrm{SRMR}=0.07 ; \mathrm{RMSEA}=0.04(\mathrm{CI} 0.03-0.05)]$ Overall CFA analysis supports the multidimensional five-factor model as the best representation of the VWB domain within each of the countries in turn and can be determined as the baseline model for each sample.

After deriving a baseline model for each sample, a configural model indicating a multigroup representation of the baseline model was examined for UK, Dutch and Turkish samples. This provides the baseline value for comparison of subsequent equivalence testing models. Using criteria suggested by Byrne (2006), measurement equivalence was determined on the basis of the fit of the multigroup model to the data and the change in robust CFI values between each analysis and the configural model. Cheung and Rensvold (2002, as cited in Byrne, 2006) suggest differences in CFI values across models should not exceed .01.

Analysis suggests that VWB scale shows equivalence across the UK, Dutch and Turkish samples (Table 2). The configural model is a reasonable fit to the data, with the Yuan-Bentler $\chi^{2}$ 
for this model similar to the sum of the values obtained for each country for the five-factor model. The imposition of equality constraints on factor loadings, factor covariances, item intercepts and latent factor means do not reduce the overall fit of the model (CFI values between .89 and .91 ; RMSEA values of .04 across analyses) and differences in the CFI are around .01. Overall model testing provides evidence to suggest the structural equivalence of the VWB scale across UK, Dutch and Turkish samples.

Insert Table 2 about here

\section{Relationships between OCB, CWB and other variables.}

Correlations between OCB and CWB factors (Table 3) show support for the multidimensional nature to these behaviours. Across countries, mean within-OCB correlations are .55 and mean within-CWB correlations are .54 , which is suggestive that factors represent unique features of a global OCB or CWB concept. Cross OCB-CWB factor correlations are too small to suggest a unidimensional structure and opposite relationship. Even when significant negative relationships emerged between CWBI and Courtesy in the UK, Greek and Turkish samples, this is still not strong enough to suggest CWBI and Courtesy are opposite poles. Patterns of relationships are similar across the UK, Greek and Turkish samples. In contrast, the Dutch sample showed positive relationships between CWB facets and OCBO and helping. A series of moderated regression analyses were also undertaken to examine if individual (rather than societal) cultural beliefs of social cynicism and dynamic externality moderated the relationships between VWB facets ${ }^{1}$. No moderating effects were found when CWB facets were predictors of OCB facets. Further, no moderating effects emerged for social cynicism on the relationship between OCB

\footnotetext{
${ }^{1}$ Data on these analyses can be obtained from the first author on request
} 
facets and CWB. Dynamic externality did moderate the relationship between OCB and CWB (although this effect only accounted for an extra $2 \%$ of the variance).

Insert Table 3 about here

Correlations with personality traits suggest a consistent pattern across cultures in relation to agreeableness and conscientiousness (Table 4). Although in all countries relationships are not necessarily significant, a profile of negative correlations between conscientiousness/agreeableness and CWB and positive correlations with OCB emerges. However, for Agreeableness correlations are not suggestive of a bi-polar relationship because stronger relationships emerge with OCB than CWB factors. Conscientiousness shows more of a bi-polar pattern, although even here there is not a consistent relationship between this trait and behaviours in all countries. The only other consistent positive relationship across countries emerges for OCBO and Intellect; however we do not see a similar, opposite, relationship between this trait and CWBO or CWBI.

Insert Table 4 about here

There is little consistent evidence for the relationship between justice dimensions and OCB/CWB across countries (Table 5). Evidence emerges of opposite relationships between organizational commitment, team commitment and OCB/CWB in the UK and Greek samples, but less so for other samples. However, in both cases not all are significant and of similar magnitude to support a bi-polar perspective.

Insert Table 5 about here

\section{Discussion}

As far as we are aware, this is the first study which has adopted a cross-cultural approach to assess the relationship between $\mathrm{OCB}$ and $\mathrm{CWB}$ and has a number of advantages over previous 
research. Firstly, to address the gap in the current literature, we considered the relationship between OCB and CWB across different cultures based on a specific cultural theory. Secondly, rather than using existing scales measuring OCB and CWB separately, we adopted a scale of OCB and CWB developed specifically to examine both constructs together within an interpersonal-organizational/productive-counterproductive framework. Additionally, this scale was developed to omit overlapping items. Thirdly, adopting the ITC Guidelines on Test Translation and Adaptation as a framework allowed us to test equivalence of the VWB scale in a structured manner (e.g. a combination of expert judgment, set rules for translation, analysis of literature and statistical analysis).

Overall, consistent with previous research (e.g. Dalal, 2005; Sackett et al., 2006) voluntary work behaviour is a multidimensional construct and facets of OCB and CWB are related but not bi-polar opposites. In the current study, VWB is captured by a five factor framework representing a productive-counterproductive/interpersonal-organizational dimensional structure and relationships between factors within VWB as well as between factors and study variables are generally not of opposite direction and of similar magnitude (the criteria Dalal used to assess bipolarity).

New to the existing literature, our research supports a more convergence than divergence cultural perspective in the relationships between OCB and CWB. Conceptually, linguistically and structurally the VWB scale was shown to be equivalent across countries. Further, similar relationships between $\mathrm{OCB}$ and CWB facets emerged, with within-facet correlations being higher on average than cross-facet correlations. Cross-facet correlations supported the nonopposite relationship with the exception being a consistent finding that CWBI and Courtesy have a negative relationship in all but the Dutch samples - although correlations were moderate at best 
(-.23 to -.46). Additionally, relationships particularly with personality and to some extent commitment did not indicate large cultural variations. Where differences emerged they tended to be with the Dutch sample (a direct control to the UK sample) than with the Turkish and Greek samples.

This convergence outcome is particularly interesting as we identified countries on the basis of a cultural model which would suggest differences in beliefs and subsequent $\mathrm{OCB} / \mathrm{CWB}$, and as the dominant view, especially within OCB research, is one of differences in the: level of engagement (Moorman \& Blakely, 1995); dimensionality (Farh, Zong, \& Organ, 2004); relationships with antecedents (Coyne \& Ong, 2007); and perceptions of extra-role nature (Kwantes, Karam, Kuo \& Towson, 2008). Although, as noted previously, this same dominant viewpoint is not prevalent for research in CWB. Therefore, it appears that the conceptualization and relationship between OCB and CWB may be culturally universal and that findings in US samples can be replicated in other non-US samples.

However, there are a number of other possible explanations for these findings. Firstly, the VWB scale used here may only capture the etic (universal) dimensions of OCB and CWB. If this were the case then one would expect to see similar findings to the US research, as assessing universal behaviours would likely lead to universal findings in the relationships between these behaviours. Indeed, items in the etic OCB dimensions reported in Chinese samples (Farh, Earley, \& Lin, 1997; Farh, Zhong, \& Organ, 2004) are similar to items in our OCBO and altruism dimensions. Also, suggestive of a universal element, the individual-organizational structure for CWB emerges in Chinese (Rotundo \& Xie, 2008) and Korean samples (Lee, Ashton \& Shin, 2005). However, in both of the Farh papers, the courtesy facet is not seen within Chinese samples and the emic Interpersonal harmony factor (Farh et al. 1997) includes items which 
resemble opposite behaviours to our CWBI scale (in effect they could be reverse scored CWBI items). This may provide some explanation to the results, but given our scale includes non-etic and even possible emic dimensions, it does not fully explain the findings.

Secondly, previous research has tended to focus on Chinese samples as a direct contrast to US samples. Here, we included European samples different in social axioms. So, perhaps contrasts in OCB will be more pronounced in US-Chinese comparisons than in US-European comparisons. Against this idea, although Hong Kong, Thailand, Korea and Taiwan are within the high DE/high SC social axioms quadrant (Bond et al) which we did not use; China is placed in the same quadrant as Greece (in fact in the same cluster).

Thirdly, there could be a methodological explanation for the findings. Dalal (2005) and Spector, Bauer, \& Fox (2010) illustrate correlations between OCB and CWB are attenuated when scales use frequency ratings, self-reports, and when antithetical items are reduced. All these 'moderators' are present in the VWB scale. Perhaps, this attenuation effect is strong enough to mask any cultural differences and it would be interesting to find out whether cultural differences are present if scales use peer reports, antithetical items and agreement ratings.

\section{Limitations}

As with any research there are limitations to the findings. Demographic factors were not controlled in each sample so any cultural differences that emerged may be due to other factors beyond country culture (e.g. job level of type). However, in mitigation, we chose samples on the basis of cross-cultural theory rather than by opportunity and given this found it difficult to control for every variable. Further, statistical analysis supports more a convergence rather than divergence cultural effect and where differences emerged they tended to be with the Dutch 
sample. Therefore, we are confident that results were not affected notably by differences in demographic variables across cultures.

We measured primarily culture at the society level, but authors such as Kwantes et al. (2008) have argued that it is not appropriate to assume that societal cultural values always reflect and individual's cultural beliefs. In defence, we also included individual measures of beliefs which appeared to support the societal level distinctions and which did not exhibit strong moderating effects on relationships between $\mathrm{OCB} / \mathrm{CWB}$. We are therefore confident that our results are not biased by using nationality as a proxy for cultural beliefs.

A third limitation is sample size. These are small for the Greek and UK samples and just about adequate for the Turkish and Dutch samples. Ideally, it would have been useful to test the structural invariance of the scale within the Greek sample, but a sample size of 70 excluded this possibility. Further analysis on large samples (and across more cultures) would be useful as a check on the robustness of these findings. Additionally, poor response rates to the peer-reported VWB scale meant that self-reported measures were used throughout. Such an approach is problematic as it is subject to common method variance (CMV) which has the potential to inflate correlations. However, Spector (2006) criticizes the notion of CMV as having a consistent impact on self-reported data. Indeed here, we do not see a regular pattern of high correlations between $\mathrm{OCB} / \mathrm{CWB}$ and other variables. Self-reported methodology is consistently used to access CWB as, given limitations in using other methods, it is seem as the most appropriate method (e.g. Fox \& Spector, 1999). As we have already indicated the use of other reports of OCB/CWB inflates the relationship between them and arguably introduces another form of bias.

\section{Practical Considerations}


From a practical perspective, it is important for organisations, especially those that operate with a multi-cultural workforce, those embracing employment migration and those large multinationals with operations in different countries, to understand experiences of and relationships between $\mathrm{OCB}$ and $\mathrm{CWB}$ in order to help them manage their human resource. For countries surveyed in this study there is a convergence in the relationships between OCB/CWB and between $\mathrm{OCB} / \mathrm{CWB}$ and other variables. This implies that the same management practices to enhance OCB and reduce CWB could be used across these countries. Additionally, given the equivalence data, organizations can use the VWB scale to assess both behaviours across these cultural groups.

Findings also indicate that OCB and CWB are distinct behaviours and whilst related are not opposite ends of a non-task behaviour continuum. This implies individuals may engage in both forms of behaviour during their working life and that interventions aimed at one behaviour will not necessarily impact on the other. For example, the use of an integrity test to select out those at risk of engaging in CWB will not necessarily increase the likelihood that those selected in will engage in high levels of OCB.

In conclusion, this study has extended the previous US-dominated research in this developing area to show that the multidimensional/similar but different hypothesis to OCB/CWB relationships is supported across different societal cultures. We have also shown that the VWB scale has evidence of equivalence across these countries and is a useful tool for assessing $\mathrm{OCB} / \mathrm{CWB}$ in different cultures. 


\section{References}

Bechtoldt, M., Welk, C., Hartig, J., \& Zapf, D. (2007). Main and moderating effects of selfcontrol, organizational justice, and emotional labour on counterproductive behaviour at work. European Journal of Work and Organizational Psychology, 16(4), 479-500. Psychology Press. doi: 10.1080/13594320701662618.

Bennett, R. J., \& Robinson, S. L. (2000). Development of a measure of workplace deviance. Journal of Applied Psychology, 85(3), 349-60. Retrieved from http://www.ncbi.nlm.nih.gov/pubmed/10900810.

Bennett, R. J., \& Stamper, C. L. (2001). Corporate citizenship and deviancy: A study of discretionary work behavior. In C. Galbraith \& M. Ryan (Eds.), International Research in the Business Disciplines: Strategies and Organizations in Transition (pp. 265-284). Amsterdam: Elsevier Science.

Bentler, P. M. (2006). EQS 6 Structural Equations Program Manual. Encino, CA: Multivariate Software Inc. Retrieved from www.mvsoft.com.

Bolino, M., Turnley, W. H., \& Niehoff, B. P. (2004). The other side of the story: Reexamining prevailing assumptions about Organizational Citizenship Behavior. Human Resource Management Review, 14(2), 229-246. doi: 10.1016/j.hrmr.2004.05.004.

Bolino, M. C., Turnley, W. H., Gilstrap, J. B., \& Suazo, M. M. (2010). Citizenship under pressure: What's a "good soldier" to do? Journal of Organizational Behavior, 31, 835-855. doi: 10.1002/job.

Bond, M. H. (2004). Culture-level dimensions of Social Axioms and their correlates across 41 cultures. Journal of Cross-Cultural Psychology, 35(5), 548-570. doi: 10.1177/0022022104268388.

Byrne, B. (2006). Structural Equation Modeling with EQS. Basic concepts, applications and programming ( $2^{\text {nd }}$ edition). Mahwah, New Jersey: Lawrence Erlbaum Associates.

Byrne, B., Shavelson, R., \& Muthen, B. (1989). Testing for the equivalence of factor covariance and mean structures: The issue of partial measurement invariance. Psychological Bulletin, $105,456-466$.

Cem Ersoy, N., Born, M. P., Derous, E., \& Molen, H. T. van der. (2011). Antecedents of organizational citizenship behavior among blue- and white-collar workers in Turkey. International Journal of Intercultural Relations, 35(3), 356-367. doi: 10.1016/j.ijintrel.2010.05.002.

Coleman, V. I., \& Borman, W. C. (2000). Investigating the underlying structure of the citizenship performance domain. Human Resource Management Review, 10(1), 25-44.

Coyne, I., \& Gentile, D. (2006). The design and development of a Voluntary Workplace Behaviour scale. Unpublished report for SHL group plc. 
Coyne, I., \& Ong, T. (2007). Organizational Citizenship Behaviour and turnover intention: A cross-cultural study. International Journal of Human Resource Management, 18(6), 10851097. doi: 10.1080/09585190701321831.

Dalal, R. S. (2005). A meta-analysis of the relationship between organizational citizenship behavior and counterproductive work behavior. Journal of Applied Psychology, 90(6), 1241-55. doi: 10.1037/0021-9010.90.6.1241.

Dalal, R. S., Lam, H., Weiss, H. M., Welch, E. R., \& Hulin, C. L. (2009). A within-person approach to work behavior and performance: Concurrent and lagged citizenshipcounterproductivity associations and dynamic relationships with affect and overall job performance. Academy of Management Journal, 52(5), 1051-1066.

Ellemers, N., Gilder, D. de, \& Heuvel, H. van den. (1998). Career-oriented versus team-oriented commitment and behavior at work. Journal of Applied Psychology, 83(5), 717-730. doi: 10.1037/0021-9010.83.5.717.

Farh, J.-L., Earley, P. C., \& Lin, S.-C. (1997). Impetus for action: A cultural analysis of justice and Organizational Citizenship Behavior in Chinese Society. Administrative Science Quarterly, 42(3), 421. doi: 10.2307/2393733.

Farh, J.-L., Zhong, C.-B., \& Organ, D. W. (2004). Organizational Citizenship Behavior in the People's Republic of China. Organization Science, 15(2), 241-253. doi: 10.1287/orsc.1030.0051.

Fox, S., \& Spector, P. E. (1999). A model of work frustration-aggression. Journal of Organizational Behavior, 20(6), 915-931. doi: 10.1002/(SICI)10991379(199911)20:6<915::AID-JOB918>3.3.CO;2-Y.

Galperin, B. L., \& Burke, R. J. (2006). Uncovering the relationship between workaholism and workplace destructive and constructive deviance: An exploratory study. International Journal of Human Resource Management, 17(2), 331-347. doi: 10.1080/09585190500404853.

Goldberg, L. R., Johnson, J., Eber, H., Hogan, R., Ashton, M., Cloninger, C., et al. (2006). The International Personality Item Pool and the future of public-domain personality measures. Journal of Research in Personality, 40, 84-96.

Gruys, M. L., \& Sackett, P. R. (2003). Investigating the dimensionality of Counterproductive Work Behavior. International Journal of Selection and Assessment, 11(1), 30-42. doi: 10.1111/1468-2389.00224.

Hambleton, R. K., \& Patsula, L. (1999). Increasing the validity of adapted tests: Myths to be avoided and guidelines for improving test adaptation practices. Journal of Applied Testing Technology, 1, 1-30.

Hofstede, G. (1980). Culture's consequences: Individual Differences in Work-related Values. Beverley Hills, CA: Sage Publications Ltd. 
Hu, L.-T., \& Bentler, P. M. (1999). Cutoff criteria for fit indexes in covariance structure analysis: Conventional criteria versus new alternatives. Structural Equation Modeling: A Multidisciplinary Journal, 6, 1-55.

Hunt, S. T. (1996). Generic work behaviour: An investigation into the dimensions of entry level, hourly job performance. Personnel Psychology, 49, 51-83.

Johns, G., \& Xie, J. L. (1998). Perceptions of absence from work: People's Republic of China versus Canada. Journal of Applied Psychology, 83(4), 515-530. doi: 10.1037//00219010.83.4.515.

Kelloway, E. K., Loughlin, C., Barling, J., \& Nault, A. (2002). Self-Reported Counterproductive Behaviors and Organizational Citizenship Behaviors: Separate but related constructs. International Journal of Selection and Assessment, 10(1\&2), 143-151. doi: 10.1111/14682389.00201.

Kwantes, C., Karam, C., Kuo, B., \& Towson, S. (2008). Culture's influence on the perception of OCB as in-role or extra-role. International Journal of Intercultural Relations, 32(3), 229243. doi: 10.1016/j.ijintrel.2008.01.007.

Lam, S. S. K., Hui, C., \& Law, K. S. (1999). Organizational Citizenship Behavior: Comparing perspectives of supervisors and subordinates across four international samples. Journal of Applied Psychology, 84(4), 594-601. doi: 10.1037/0021-9010.84.4.594.

Lee, K., Ashton, M. C., \& Shin, K.-H. (2005). Personality correlates of Workplace Anti-Social Behavior. Applied Psychology: An International Review, 54(1), 81-98.

Lepine, J. A., Erez, A., \& Johnson, D. E. (2002). The nature and dimensionality of Organizational Citizenship Behavior: A critical review and meta-analysis. Journal of Applied Psychology, 87(1), 52- 65. doi: 10.1037//0021-9010.87.1.52.

Marcus, B., Schuler, H., Quell, P., \& Humpfner, G. (2002). Measuring counterproductivity: Development and initial validation of a German self-report questionnaire. International Journal of Selection and Assessment, 10(1/2), 18-35.

Meade, A. W., \& Kroustalis, C. M. (2006). Problem with item parceling for confirmatory factor analytic tests of measurement invariance. Organizational Research Methods, 9(3), 369-403. doi: $10.1177 / 119442 \times 105283384$.

Moorman, R. H., \& Blakely, G. L. (1995). Individualism-collectivism as an individual difference predictor of Organizational Citizenship Behavior. Journal of Organizational Behavior, 16, 127-142.

Moorman, R. H. (1991). Relationship between organizational justice and Organizational Citizenship Behaviors: Do fairness perceptions influence employee citizenship? Journal of Applied Psychology, 76(6), 845-855. doi: 10.1037/0021-9010.76.6.845.

Organ, D. W. (1988). Organizational Citizenship Behavior: The Good Soldier Syndrome. Lexington, MA: Lexington Books. 
Organ, D. W., \& Lingl, A. (1995). Personality, satisfaction and Organizational Citizenship Behaviour. The Journal of Social Psychology, 135(339-350).

O'Brien, K. E., \& Allen, T. D. (2008). The relative importance of correlates of Organizational Citizenship Behavior and Counterproductive Work Behavior using multiple sources of data. Human Performance, 21, 62-88. doi: 10.1080/08959280701522189.

Paine, J. B., \& Organ, D. W. (2000). The cultural matrix of Organizational Citizenship Behavior: Some preliminary conceptual and empirical observations. Human Resource Management Review, 10(1), 45-59.

Podsakoff, N. P., Whiting, S. W., Podsakoff, P. M., \& Blume, B. D. (2009). Individual- and organizational-level consequences of Organizational Citizenship Behaviors: A metaanalysis. Journal of Applied Psychology, 94(1), 122-41. doi: 10.1037/a0013079.

Podsakoff, P. M., Mackenzie, S. B., Paine, J. B., \& Bachrach, D. G. (2000). Organizational Citizenship Behaviors : A critical review of the theoretical and empirical literature and suggestions for future research. Journal of Management, 26(3), 513-563.

Price, J. L., \& Mueller, C. W. (1986). Handbook of Organizational Measurement. Marshfield, M.A. Pittman.

Rogers, K., \& Kelloway, E. K. (1997). Violence at work: Building healthy workplaces: Personal and organizational outcomes. Journal of Occupational Health Psychology, 2, 63-71.

Rotundo, M., \& Sackett, P. R. (2002). The relative importance of task, citizenship, and counterproductive performance to global ratings of job performance: A policy-capturing approach. Journal of Applied Psychology, 87, 66-80. doi: doi: 10.1037/0021-9010.87.1.66.

Rotundo, M., \& Xie, J. L. (2008). Understanding the domain of Counterproductive Work Behavior in China. The International Journal of Human Resource Management, 19(5), 856877. doi: 10.1080/09585190801991400.

Sackett, P. R. (2002). The structure of Counterproductive Work Behaviors: Dimensionality and relationships with facets of job performance. International Journal of Selection and Assessment, 10(1\&2), 5-11. doi: 10.1111/1468-2389.00189.

Sackett, P. R., Berry, C., Wiemann, S., \& Laczo, R. (2006). Citizenship and Counterproductive Behavior: Clarifying relations between the two domains. Human Performance, 19(4), 441464. doi: 10.1207/s15327043hup1904_7.

Smith, C. A., Organ, D. W., \& Near, J. P. (1983). Organizational Citizenship Behavior: Its nature and antecedents. Journal of Applied Psychology, 68(4), 653-663. doi: 10.1037/00219010.68.4.653.

Spector, P. E. (2006). Method variance in organizational research: Truth or urban legend? Organizational Research Methods, 9(2), 221-232. doi: 10.1177/1094428105284955.

Spector, P. E., Bauer, J. A., \& Fox, S. (2010). Measurement artifacts in the assessment of Counterproductive Work Behavior and Organizational Citizenship Behavior: Do we know 
what we think we know? Journal of Applied Psychology, 95(4), 781-90. doi: 10.1037/a0019477.

Spector, P. E., \& Fox, S. (2005). Concluding thoughts: Where do we go from here? In S. Fox \& Paul E Spector (Eds.), Counterproductive work behavior: Investigations of actors and targets (pp. 297-305). Washington: American Psychological Association.

Spector, P. E., \& Fox, S. (2010a). Counterproductive Work Behavior and Organisational Citizenship Behavior: Are they opposite forms of active behavior? Applied Psychology: An International Review, 59(1), 21-39. doi: 10.1111/j.1464-0597.2009.00414.x.

Spector, P. E., \& Fox, S. (2010b). Theorizing about the deviant citizen: An attributional explanation of the interplay of organizational citizenship and counterproductive work behavior. Human Resource Management Review, 20(2), 132-143. Elsevier Inc. doi: 10.1016/j.hrmr.2009.06.002.

Van de Vijver, F. J., \& Jeanrie, C. (2004). Assessing structural and metric equivalence: A case study. Paper presented at the 28th International Congress of Psychology. Beijing.

Van Dyne, L., Vandewalle, D., Kostova, T., Latham, Michael, A., \& Cummings, L. L. (2000). Collectivism, propensity to trust and self-esteem as predictors of organizational citizenship in a non-work setting. Journal of Organizational Behavior, 21, 3-23.

Van Scotter, J. (2000). Relationships of task performance and contextual performance with turnover, job satisfaction, and affective commitment. Human Resource Management Review, 10(1), 79-95. doi: 10.1016/S1053-4822(99)00040-6. 
Table 1. CFA analysis for the VWB 25 item scale for across development and validation samples.

\begin{tabular}{|c|c|c|c|c|c|}
\hline & & 1-factor & 2-factor & 4-factor & 5-factor \\
\hline \multirow{4}{*}{$\begin{array}{l}\text { Development } \\
(\mathrm{N}=283)\end{array}$} & $\mathrm{Y}-\mathrm{B} x^{2}$ & $\begin{array}{l}950.57 \\
(275)\end{array}$ & $\begin{array}{l}647.98 \\
(274)\end{array}$ & $\begin{array}{l}524.53 \\
(269)\end{array}$ & $\begin{array}{l}422.74 \\
(265)\end{array}$ \\
\hline & CFI & .59 & .77 & .85 & .91 \\
\hline & SRMR & .17 & .08 & .07 & .06 \\
\hline & $\begin{array}{l}\text { RMSEA } \\
90 \% \text { conf }\end{array}$ & $\begin{array}{l}.09 \\
(.09-.10)\end{array}$ & $\begin{array}{l}.07 \\
(.06-.08)\end{array}$ & $\begin{array}{l}.06 \\
(.05-.06)\end{array}$ & $\begin{array}{l}.05 \\
(.04-.05)\end{array}$ \\
\hline \multirow{4}{*}{$\begin{array}{l}\text { Validation } \\
(\mathrm{N}=280)\end{array}$} & $\mathrm{Y}-\mathrm{B} x^{2}$ & $\begin{array}{l}888.35 \\
(275)\end{array}$ & $\begin{array}{l}567.30 \\
(274)\end{array}$ & $\begin{array}{l}460.24 \\
(269)\end{array}$ & $\begin{array}{l}389.58 \\
(265)\end{array}$ \\
\hline & CFI & .64 & .83 & .89 & .92 \\
\hline & SRMR & .14 & .08 & .07 & .06 \\
\hline & $\begin{array}{l}\text { RMSEA } \\
90 \% \text { conf }\end{array}$ & $\begin{array}{l}.09 \\
(.08-.10)\end{array}$ & $\begin{array}{l}.06 \\
(.05-.07)\end{array}$ & $\begin{array}{l}.05 \\
(.04-.06)\end{array}$ & $\begin{array}{l}.04 \\
(.03-.05)\end{array}$ \\
\hline
\end{tabular}

Y-B $x^{2}$ - Yuan-Bentler scaled statistic. Corrected CFI and RMSEA reported. Chi-square values all significant at $\mathrm{p}<0.01$ 
Table 2. Tests of measurement equivalence for VWB scale across countries

\begin{tabular}{|l|c|r|r|r|r|c|}
\hline & $\mathrm{Y}^{-} \mathrm{B}_{X}^{2}$ & $\mathrm{df}$ & CFI & $\Delta$ CFI & RMSEA & $90 \%$ C.I \\
\hline Configural model & 1049.49 & 795 & .908 & - & .04 & $.03-.05$ \\
\hline $\begin{array}{l}\text { Equal factor } \\
\text { loadings }\end{array}$ & 1120.72 & 835 & .894 & .014 & .04 & $.03-.05$ \\
\hline $\begin{array}{l}\text { Equal factor } \\
\text { covariances }\end{array}$ & 1134.88 & 851 & .895 & .013 & .04 & $.03-.05$ \\
\hline $\begin{array}{l}\text { Equal item } \\
\text { intercepts }\end{array}$ & 1405.82 & 899 & .911 & .003 & .05 & $.04-.05$ \\
\hline $\begin{array}{l}\text { Equal latent factor } \\
\text { means }\end{array}$ & 1186.25 & 870 & .907 & .001 & .04 & $.03-.05$ \\
\hline
\end{tabular}

Y-B $x^{2}$ - Yuan-Bentler scaled statistic. Robust CFI and RMSEA reported 
Table 3. Correlations between VWB factors across countries - 25 item scale

\begin{tabular}{|c|c|c|c|c|c|c|c|c|c|c|}
\hline & CWBO & CWBI & OCBO & Court & Help & CWBO & CWBI & OCBO & Court & Help \\
\hline & \multicolumn{5}{|c|}{ UK (105) } & \multicolumn{5}{|c|}{ Netherlands (203) } \\
\hline CWBO & $(0.62)$ & & & & & $(0.65)$ & & & & \\
\hline CWBI & 0.43 & $(0.80)$ & & & & 0.59 & $(0.75)$ & & & \\
\hline OCBO & 0.06 & 0.10 & $(0.86)$ & & & $0.18^{*}$ & $0.22 * *$ & $\begin{array}{l}(0.78) \\
\end{array}$ & & \\
\hline Court & -0.07 & $-0.23^{* *}$ & 0.44 & $(0.81)$ & & 0.04 & 0.02 & 0.47 & $(0.75)$ & \\
\hline \multirow[t]{2}{*}{ Help } & 0.08 & 0.12 & 0.65 & 0.58 & $(0.84)$ & $0.15 *$ & 0.14 & 0.68 & 0.57 & $(0.83)$ \\
\hline & \multicolumn{5}{|c|}{ Turkey (185) } & \multicolumn{5}{|c|}{ Greece (70) } \\
\hline CWBO & $(0.76)$ & & & & & $(0.69)$ & & & & \\
\hline CWBI & 0.70 & $(0.82)$ & & & & $0.44 * *$ & $(0.68)$ & & & \\
\hline OCBO & -0.06 & -0.05 & $(0.83)$ & & & -0.05 & -0.04 & $(0.78)$ & & \\
\hline Court & $-0.24 * *$ & -0.29 & 0.54 & (0.79) & & -0.21 & -0.46 & $0.36^{* *}$ & $(0.70)$ & \\
\hline Help & -0.09 & -0.02 & 0.62 & 0.60 & $(0.79)$ & -0.01 & -0.06 & 0.56 & 0.58 & $(0.79)$ \\
\hline
\end{tabular}

$*=\mathrm{p}<0.05 ; * *=\mathrm{p}<0.01 ;$ Bold $=\mathrm{p}<0.001$ 
Table 4. Correlations between VWB factors and personality across countries - 25 item scale

\begin{tabular}{|c|c|c|c|c|c|c|c|c|c|c|}
\hline & CWBO & CWBI & OCBO & Court & Help & CWBO & CWBI & OCBO & Court & Help \\
\hline & \multicolumn{5}{|c|}{ UK (105) } & \multicolumn{5}{|c|}{ Netherlands (203) } \\
\hline Extr & -0.12 & 0.11 & 0.16 & -0.16 & 0.02 & -0.01 & -0.03 & 0.28 & 0.25 & 0.30 \\
\hline Agree & -0.19 & -0.37 & 0.36 & 0.45 & 0.34 & -0.08 & -0.12 & 0.26 & 0.39 & 0.35 \\
\hline Cons & $-0.30^{* *}$ & -0.13 & 0.35 & $0.26^{* *}$ & $0.30 * *$ & -0.28 & $-0.18^{* *}$ & 0.26 & $0.23 *$ & 0.28 \\
\hline Emot & -0.45 & $-0.21 *$ & $0.23 *$ & 0.04 & 0.15 & $-0.19 * *$ & -0.11 & 0.08 & 0.13 & 0.09 \\
\hline \multirow[t]{2}{*}{ Intell } & 0.06 & 0.06 & $0.25^{*}$ & 0.15 & 0.03 & -0.05 & -0.04 & 0.28 & 0.32 & 0.30 \\
\hline & \multicolumn{5}{|c|}{ Turkey (185) } & \multicolumn{5}{|c|}{ Greece (70) } \\
\hline Extr & 0.03 & -0.03 & 0.11 & 0.01 & 0.08 & 0.22 & 0.02 & $0.39 * *$ & 0.16 & $0.27 *$ \\
\hline Agree & $-0.22 * *$ & $-0.25^{* *}$ & 0.30 & 0.38 & 0.36 & -0.07 & -0.19 & $0.31 * *$ & 0.49 & 0.47 \\
\hline Cons & -0.29 & -0.30 & 0.14 & $0.20 *$ & $0.22 * *$ & $-0.37 * *$ & -0.02 & $0.33^{* *}$ & $0.28^{*}$ & 0.10 \\
\hline Emot & $-0.16^{*}$ & -0.12 & 0.08 & $0.20 *$ & 0.07 & -0.10 & -0.19 & 0.06 & -0.03 & 0.03 \\
\hline Intell & -0.09 & -0.01 & $\mathbf{0 . 3 0}$ & 0.15 & 0.32 & 0.06 & -0.04 & 0.57 & $0.29 *$ & 0.42 \\
\hline
\end{tabular}

$*=\mathrm{p}<0.05 ; * *=\mathrm{p}<0.01 ;$ Bold $=\mathrm{p}<0.001$ 
Table 5. Correlations between VWB factors and fairness and commitment across countries - 25 item scale

\begin{tabular}{|c|c|c|c|c|c|c|c|c|c|c|}
\hline & CWBO & CWBI & OCBO & Court & Help & CWBO & CWBI & OCBO & Court & Help \\
\hline & \multicolumn{5}{|c|}{ UK (105) } & \multicolumn{5}{|c|}{ Netherlands (203) } \\
\hline DisJus & -0.10 & -0.13 & -0.01 & -0.03 & -0.06 & -0.07 & -0.13 & -0.13 & -0.09 & -0.05 \\
\hline ProJus & -0.19 & -0.32 & 0.14 & $0.23 *$ & 0.08 & $-0.18 * *$ & $-0.16^{*}$ & -0.13 & -0.03 & 0.09 \\
\hline CCom & -0.05 & -0.15 & $0.22 *$ & 0.12 & -0.02 & 0.11 & 0.10 & 0.25 & 0.08 & 0.11 \\
\hline TCom & -0.12 & -0.13 & 0.37 & $0.29 * *$ & $0.22 *$ & -0.07 & -0.03 & 0.33 & 0.25 & 0.29 \\
\hline \multirow[t]{2}{*}{ OCom } & $-0.27 * *$ & $-0.21 *$ & $0.28 * *$ & $0.27 * *$ & $0.22 *$ & -0.02 & -0.03 & $0.23 * *$ & 0.03 & $0.17 *$ \\
\hline & \multicolumn{5}{|c|}{ Turkey (185) } & \multicolumn{5}{|c|}{ Greece (70) } \\
\hline DisJus & $0.23 *$ & 0.11 & -0.13 & -0.02 & -0.03 & 0.10 & -0.06 & 0.17 & -0.03 & 0.10 \\
\hline ProJus & $0.15^{*}$ & 0.05 & 0.01 & 0.07 & 0.07 & -0.02 & -0.22 & $0.31^{* *}$ & 0.21 & 0.23 \\
\hline CCom & $-0.16^{*}$ & $-0.22 * *$ & 0.28 & 0.40 & 0.14 & -0.05 & -0.20 & 0.54 & 0.41 & 0.32 \\
\hline TCom & 0.01 & -0.02 & 0.33 & 0.41 & $0.25 * *$ & $-0.28 *$ & $-0.31 *$ & 0.44 & 0.60 & $0.37 * *$ \\
\hline OCom & -0.05 & -0.13 & $0.21^{* *}$ & 0.33 & 0.06 & -0.17 & -0.12 & 0.42 & $0.40 * *$ & $0.30^{*}$ \\
\hline
\end{tabular}

$*=\mathrm{p}<0.05 ; * *=\mathrm{p}<0.01 ;$ Bold $=\mathrm{p}<0.001$ 